\title{
COMBUSTION INFLUENCE ON A BEARING KNOCK NOISE ISSUE FOR A DIESEL ENGINE
}

\author{
Giulliano Humberto Capana, Mauro Miguel Pecula and Angelo Alves Leite. \\ MWM Motores Diesel \\ E-mails: giulliano.capana@ @avistar.com.br, mauro.pecula@ navistar.com.br, and \\ angelo.leite@ navistar.com.br.
}

\begin{abstract}
The impulsive noise can have several sources in internal combustion (IC) engines, such as geared pairs and nozzles and its own cyclical operation. It can cause a considerable annoyance, especially when modulated by minor orders, affecting the sound quality of the engine and consequently the image of the product to customers.
\end{abstract}

IC engines have severe operating conditions, involving high temperatures and high pressures, with large variations in internal forces within each cycle. The bearings are particularly vulnerable to these conditions, because of the extreme variations in load.

This paper approaches a diesel engine bearing knock noise issue noticed at low speeds and loads in a Brazilian Proconve 7 truck application.

During the investigation process several root causes were raised as well as potential corrective actions. It was detected that the main source of the noise was coming from one of the main bearings and that combustion plays a significant role over the noise.

Although mechanical measures are also considered on this study special focus is given to combustion as calibration solution represents lower costs when comparing to design changes.

The outputs obtained from sweeps and DoE methodologies performed especially for combustion parameters revealed that splitting injection is one of the best approach for reducing the noise. Another solution proven to be effective is the $6^{\text {th }}$ cylinder injector shut off during idling and low load operation.

Both calibration options dramatically reduced noise but, besides fulfilling emissions legislation, splitting injection resulted in white smoke emission at cold temperatures so that injector shut off has been implemented as the solution for massive production.

Throughout a dataset update via electronic control unit (ECU) flash, such solution has been implemented in several trucks in the field and it has been proven to be effective in solving bearing knock noise complaint. 


\section{INTRODUCTION}

\subsection{DESCRIPTION OF NOISE ISSUE.}

Problems with noise can affect several aspects such as legal, when it does not fulfil some emission legislation per the type of source and application, contractual, where it is the responsibility of the supplier to meet a contractor's noise criteria and sound quality aspects, when the noise may cause some disturbance to the users or other people subjected to it even without affect legal or contractual criteria.

The bearing knock noise issue approached in this paper is regarding a sound quality problem, it does not affect legal (pass by noise) or contractual limits (sound power emitted by the engine). In addition, there are no side effects to the engine, such as premature wear, low performance, high fuel consumption, etc.

The characteristic of the noise is impulsiveness, short time duration with large spectral content [1], and in this case, also lack of consistency. Although it happens every two turns of the engine sometimes there is a period without being noticed. This fact causes the impression of malfunction, so it falls in the scope of sound quality. Although not causing any harm to the engine it promotes an unpleasant sensation to the user [2].

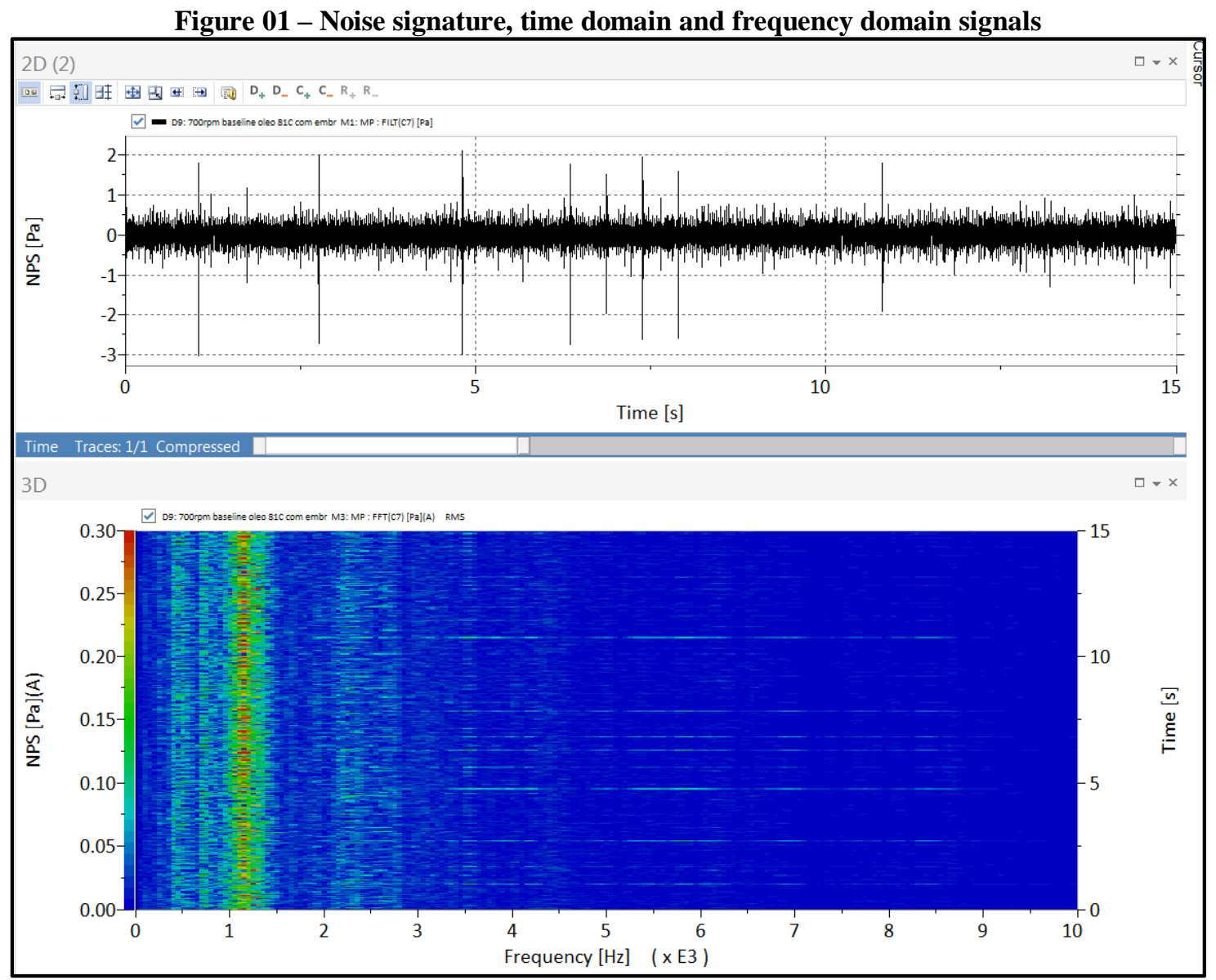


The upper graph in figure 01 shows in the time domain signal some short time spikes which represents the noise itself and the lower graph shows the frequency content of the spikes mainly from $3000 \mathrm{~Hz}$ to $9000 \mathrm{~Hz}$.

The noise is noticed in low-rev and low-load conditions, especially at idle, and only when the engine is warmed up. In most of the cases the noise is noticed only from the outside of the vehicle.

\subsection{SOURCE OF THE NOISE}

There are a lot impulsive noise sources in an internal combustion engine [3], the main sources were listed in a fault tree to support the investigation.

Figure 02 - Fault tree - Main causes of impulsive noise in IC engines

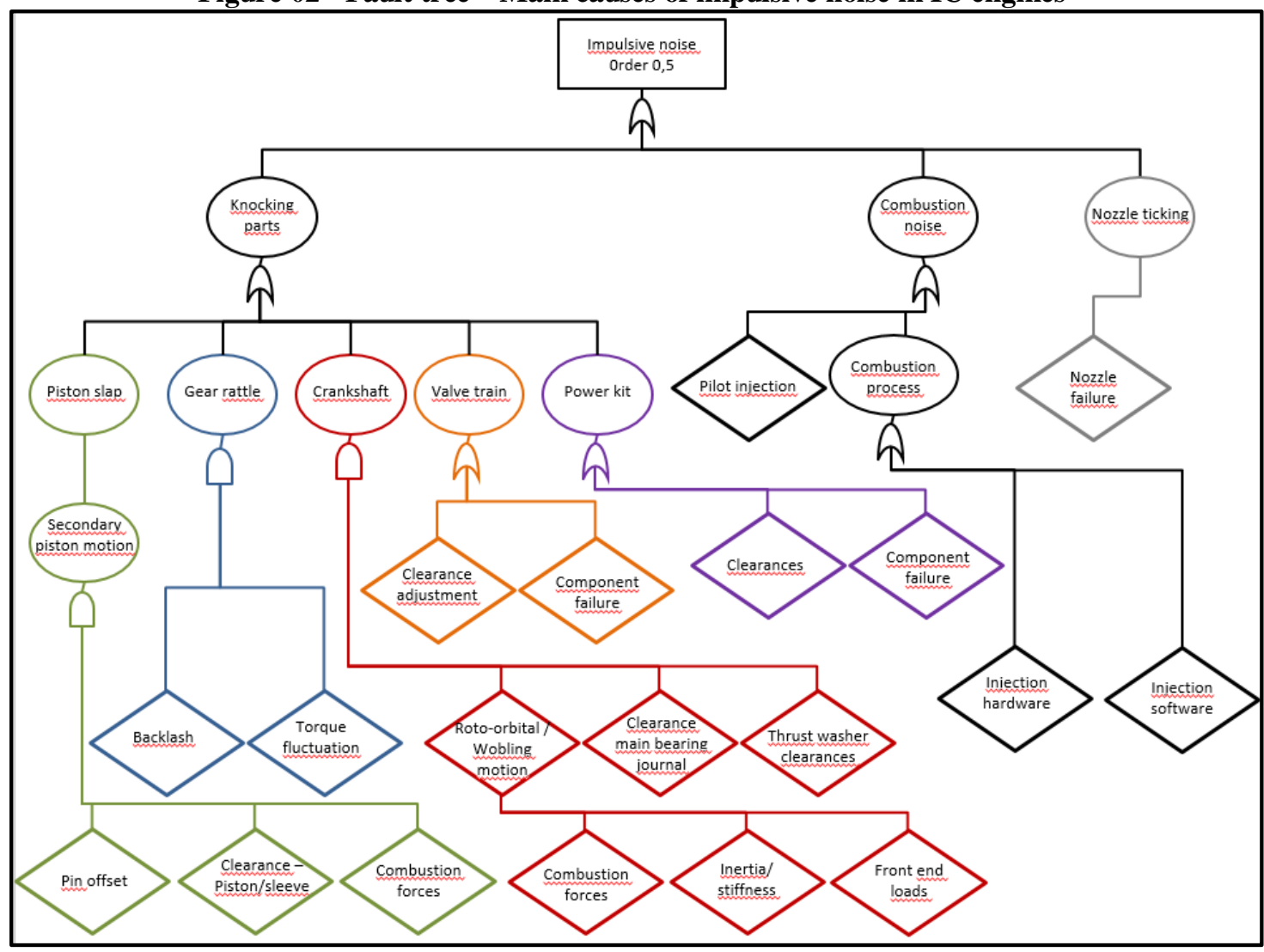

Considering the difficulty to find out impulsive sources a set of techniques was employed to identify the noise source, especially considering the peculiarity of the noise and number of presumed root causes.

The techniques employed were noise/vibration signature survey, acoustic holography and time delay vibration response.

The noise source was found to be close to the fifth main bearing region, which suggested the presence of bearing knock noise.

The bearing knock noise occurs due to the impact of the crankshaft on the main bearing shells. 
Per the literature and tests performed during the research, the main factors that contribute to the presence of this noise are:

- Oil thickness of hydrodynamic bearing [4] / main bearing clearances [3]

- Crankshaft movements [5] / operational and natural modes [6]

- Damping [7] / materials and lubricating oil [8]

All those factors have been evaluated through sensitive tests with the intention of validating that bearing knock noise is occurring and all tests converged to confirm such hypothesis.

The sensitivity tests performed with direct intervention in noise response was:

- Changing in bearing clearance

- Changing of the masses involved in the system (rotational parts like flywheel and clutch).

- Changing of combustion force (number of injections or no injection in 6th cylinder)

- Changing of oil specification

- Temperature of oil

Another characteristic of the noise is that when the fuel injector from sixth cylinder is shut off, only the sixth, the noise is eliminated. This condition seems to happen due to the vibration modes of the crankshaft. When the excitation comes from the sixth cylinder (combustion) the crankshaft has a response (a vibrating mode and amplitude) that induces a movement and consequently impact in the region of the fifth main bearing. Further tests are necessary for confirmation of this theory / hypothesis. This phenomenon is shown in figure 03.

Figure 03 - Vibration with and without 6th injector working

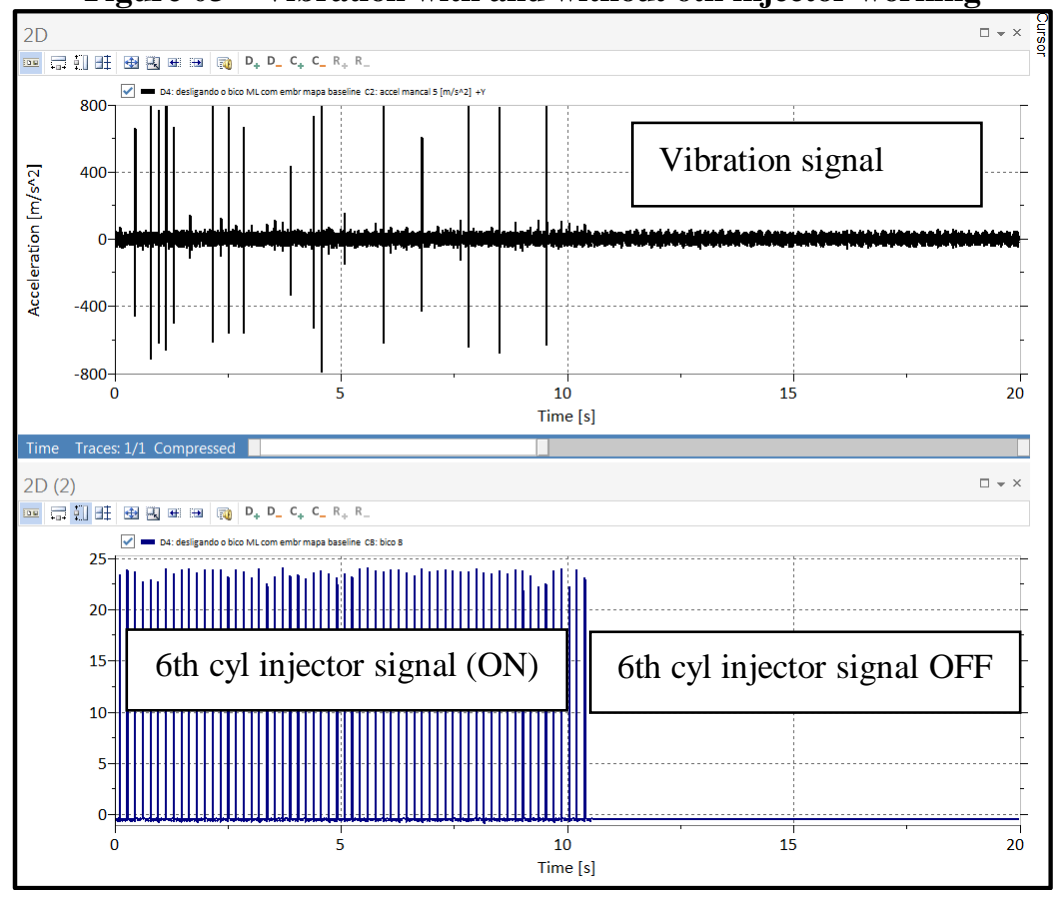

In tests of sensitivity between combustion and noise, both actions, the shutdown of cylinder \# 6 and smoothing of the combustion pressure curve had positive effects, eliminating noise as shown in figures 03 and 04. 
Figure 04 Combustion pressure curve shape vs Acceleration

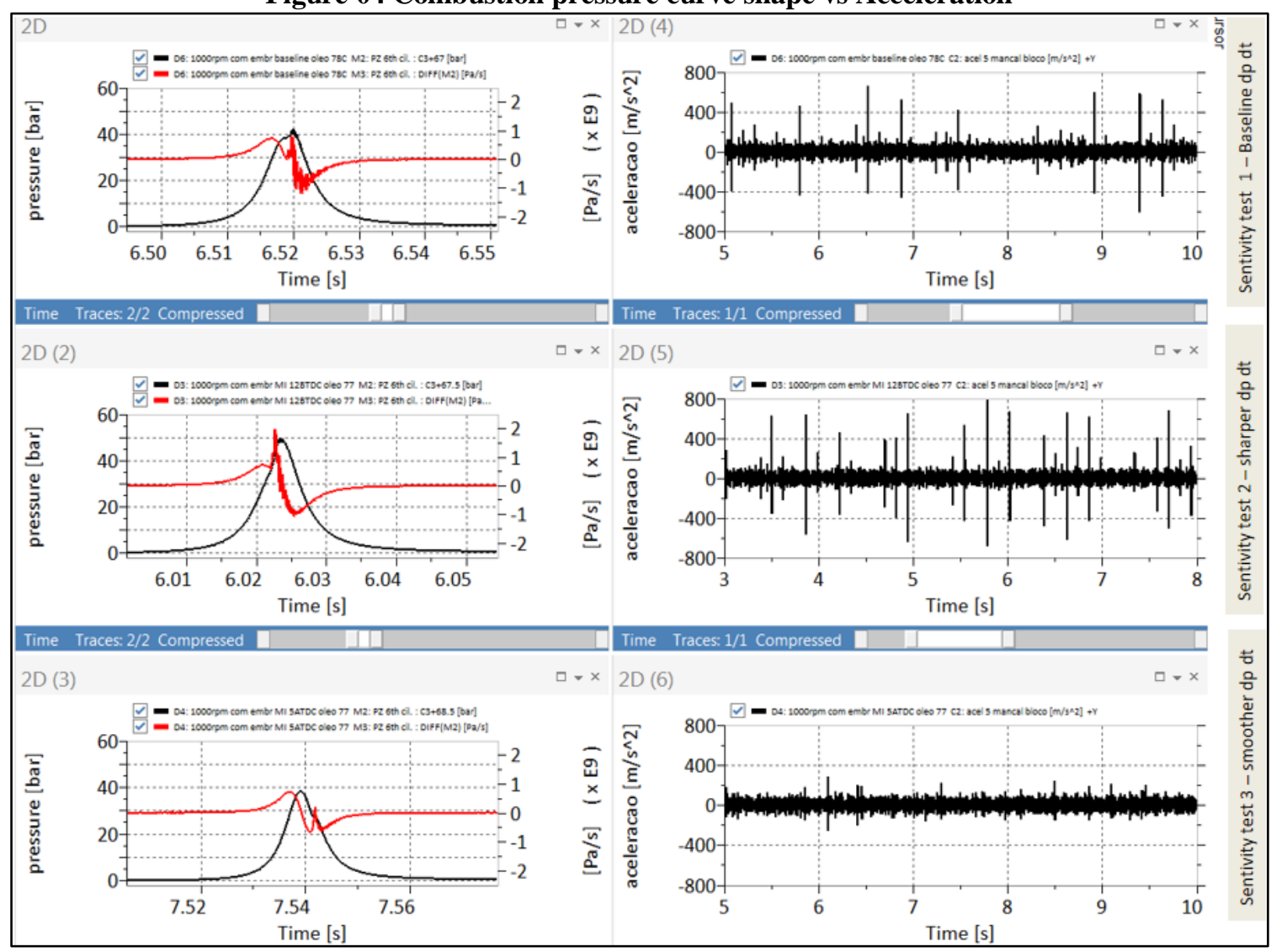

Figure 04 shows a clear influence of combustion pressure over the noise. It is possible to realize that a faster delta pressure increase over the time ( $\mathrm{dp} \mathrm{dt}$ ) produces higher noise incidence. This is due to the force produced by the combustion in the crankcase and bearing shells. As sharper as the pressure variation is, higher is the noise incidence. So, changes on calibration of combustion parameters could result in significant reduction of the noise as well as the 6th cylinder injector shut-off.

Smoothing the combustion pressure reduces the sharp effect of $\mathrm{dp} d \mathrm{dt}$ avoiding the break in of the oil film and so the micro-contact that causes the bearing knock noise. This happens mainly at low speeds where the hydrodynamic bearing works in a region of transition between boundary and full-film lubrication.

Changes in clearances and material would also cause influence over the noise but it would result in many hours of redesign, tooling development, several qualification tests and consequently very high costs. So, the best option to eliminate noise in a short time is decided to be through the combustion parameters changes. In parallel, a calibration proposal for shutting off the 6th cylinder injector just in low speeds and low load area will also be prepared. After evaluating both proposals in the field the best alternative is intended to be implemented for massive production.

The best method developed to identify and quantify the presence of noise and its level was through the temporal signal of the vibration of the crankcase close to the fifth main bearing. This vibration in crankcase has been used for the DoE of the combustion parameters. 
To standardize and assure better accuracy from the measurements a method that takes in consideration the acquisition time, number of spikes and amplitude average is defined and then used for all the investigation conducted in dynamometer and vehicle as well.

Acceleration peaks below $200 \mathrm{~m} / \mathrm{s}^{2}$ were disregarded in the analysis because they were neither audible nor identified in the noise signals. Every measurement will be evaluated in a 15 s-time basis and the number of spikes and average amplitude will be the main outputs for the analysis.

Fig 05 correlates the noise and vibration filtered signals where it is possible to link accelerations higher than $200 \mathrm{~m} / \mathrm{s}^{\wedge} 2$ with the sound pressure produced when the bearing knock noise occurs.

Figure 05 - Correlation between noise and vibration filtered signals.

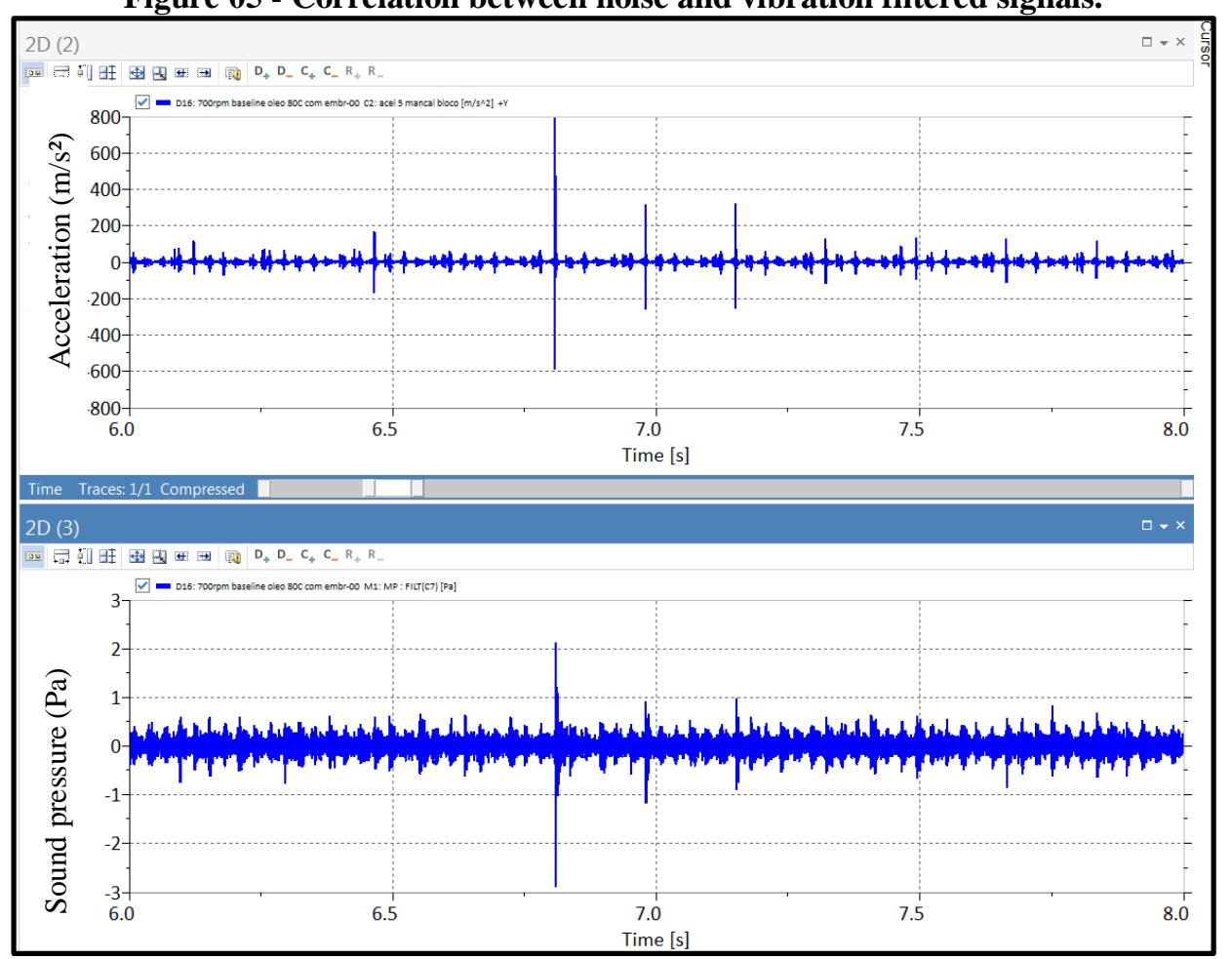

\section{METHODOLOGY}

The aim of this work is to evaluate the influence of combustion calibration parameters that may directly affect the bearing knock noise and so to find out a compromise that could reduce the noise to an acceptable value without jeopardizing other important aspects from the application such as fuel consumption and emissions.

The details of the engine which is presenting the bearing knock noise issue is show in table 1 . 
Table 1 - Engine characteristics.

\begin{tabular}{|c|c|}
\hline Type & 4 Stroke SI \\
\hline Number of cylinders & 6 in line \\
\hline Aspiration & Turbocharged After-cooled \\
\hline Compression ratio & $16.8: 1$ \\
\hline Low/high idle speed & $700 / 2550 \mathrm{rpm}$ \\
\hline ECU & EDC7UC31 \\
\hline Injection Device & Common rail (Bosch) \\
\hline Cubic displacement (l) & 7,8 \\
\hline Rated horsepower & 220 to 330cv @ 2200 rpm \\
\hline
\end{tabular}

It is used in a Brazilian truck that fulfil Proconve 7 (equivalent to Euro V) emissions legislation. To meet emissions legislation, the vehicle uses a SCR (selective catalytic reduction) after treatment system with vanadium catalyst technology and a slip-cat to reduce ammonia slip.

The study is performed on the engine operating points where the noise is audible, which are from idle speed to 1200rpm and from 0 to around $100 \mathrm{~N} . \mathrm{m}$. All changes on the combustion parameters will be applied only in this range. The aspects that should be taken into account is regarding not significantly jeopardizing fuel consumption and not surpassing emissions limits. The idle speed is one of the emissions point in ESC (European steady state cycle) and the other areas from the window under investigation has also some influence on ETC cycle (European Transient Cycle). This means that an emissions evaluation is also required after preparing a dataset proposal.

Essentially the work is focused on an appropriate selection of combustion parameters, which should have influence over the studied noise.

To organize the work and assure a successful result the research is divided in 5 phases, as listed below:

1 - Sweep methodology

2 - Response surface (DoE)

3 - Model validation

4 - Dataset proposals preparation

5 - Dataset validation

A steady state dynamometer was used to perform the tests for phases 1 to 4 and a transient dyno was also used to evaluate the emissions influence of each dataset proposal. The tests were performed in an engine that was brought from the field with a clear presence of the bearing knock noise. Phase 5 was evaluated on several vehicles in the field that was also presenting such issue.

Before starting phase 1 the baseline condition of the engine has been measured and the results in terms of spikes and amplitude can be noticed in figure 06 . 
Figure 06 - spikes and amplitude for baseline condition (idle speed)

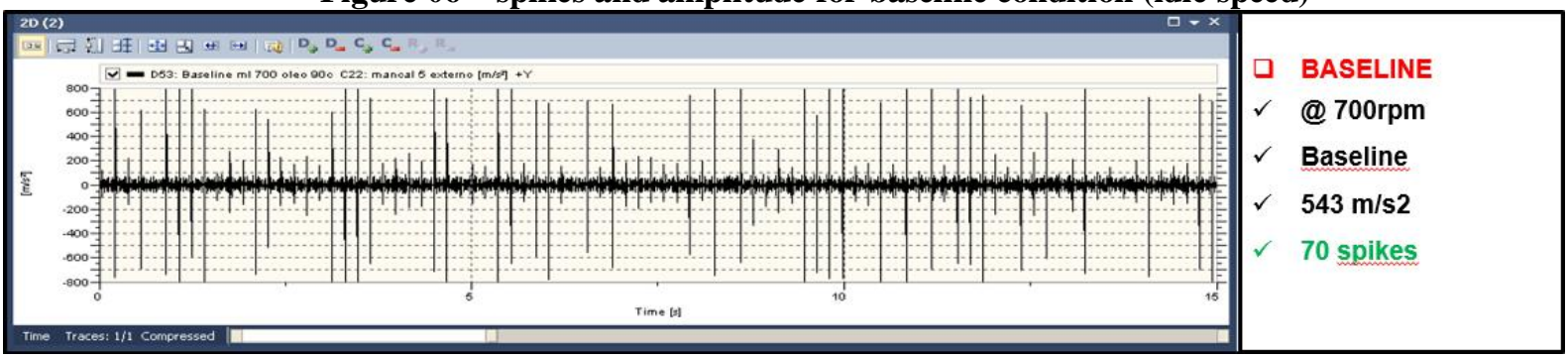

It is important to emphasize that clutch from the vehicle had also to be installed on the engine/dynamometer, otherwise the noise would not be reproducible. Clutch produces a mass/inertia that makes the system more sensitive for the noise occurrence.

Once there is a huge influence over the noise occurrence from the oil viscosity all tests were performed after engine is warmed up to $90^{\circ} \mathrm{C}$. As warmer as the engine is worst is the noise occurrence and amplitude.

Figure 07 shows the oil temperature influence over the noise, where the number of spikes becomes much higher in region where oil temperature is higher than $90^{\circ} \mathrm{C}$.

Figure 07 -Influence of oil temperature over the noise (baseline dataset / oil from 95 to $86^{\circ} \mathrm{C}$ )

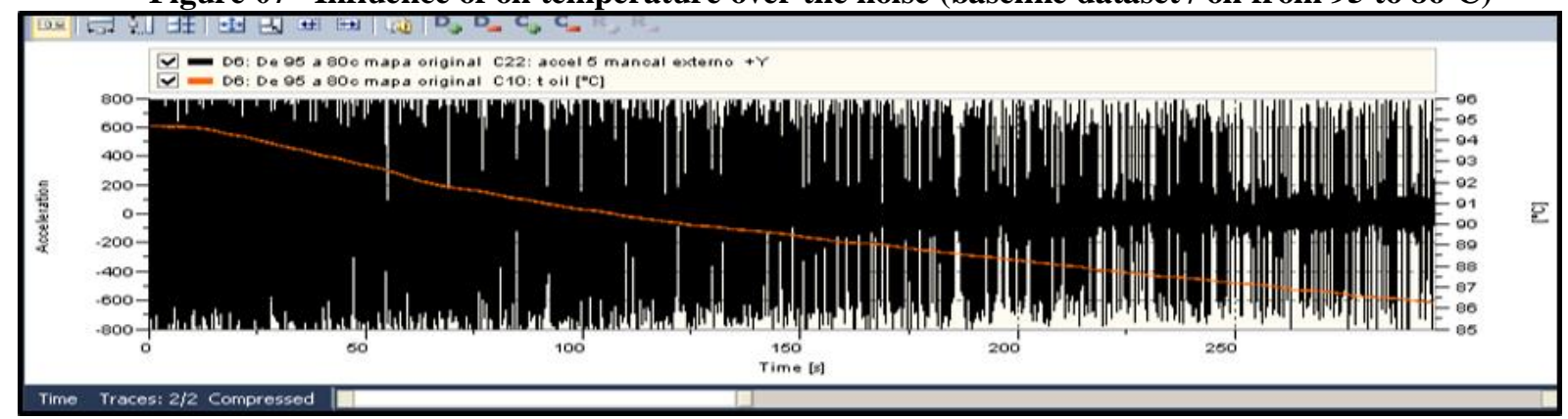

All cases investigated on the field has shown noise complaint in around $80^{\circ} \mathrm{C}$ of oil temperature. Reminding that noise occurs in very low speeds and load areas where oil tends to be in lower temperatures. Finding a solution in $90^{\circ} \mathrm{C}$ temperature area tends to cover all cases in the field.

\subsection{Sweep methodology}

To be able to define which should be the most important parameters a sweep methodology is applied. Sweep method is a fast way to find out the relevant variables reducing the number of factors and interactions to be further studied, focusing just on the ones that directly influence on the noise.

The parameters initially chosen for the sweeps are idle speed, fuel rail pressure, start of main injection and injection split.

Table 2 shows each of the factors, the minimal and maximal values and the steps in between used for the sweeping process. 
Table 2 - Factors and values used in the sweep

\begin{tabular}{|l|c|c|c|}
\hline \multicolumn{1}{|c|}{ FACTORS } & MIN & MAX & STEP \\
\hline Engine speed & 600 & 1200 & 100 \\
\hline SOI mai & 10 ATDC & 14 BTDC & 2 \\
\hline Rail pressure & 300 & 800 & 100 \\
\hline Injection Split & 2 & 4 & 1 \\
\hline
\end{tabular}

Those factors are then individually tested and its influence over the noise is evaluated by analyzing the number of spikes and amplitude occurrence.

Figure 08 brings the outputs from one of the factors where its contribution to the noise occurrence is noticeable. In this case, it is related to start of main injection (timing) where the influence by sweeping from before top dead center (negative values) to after top dead center (positive values) over the number of spikes is very clear. Also, there is a clear evidence that late main injection helps in reducing the number of spikes.

Figure 08 -Sweep outputs (noise spikes and amplitude) - Start of main injection (SOI)

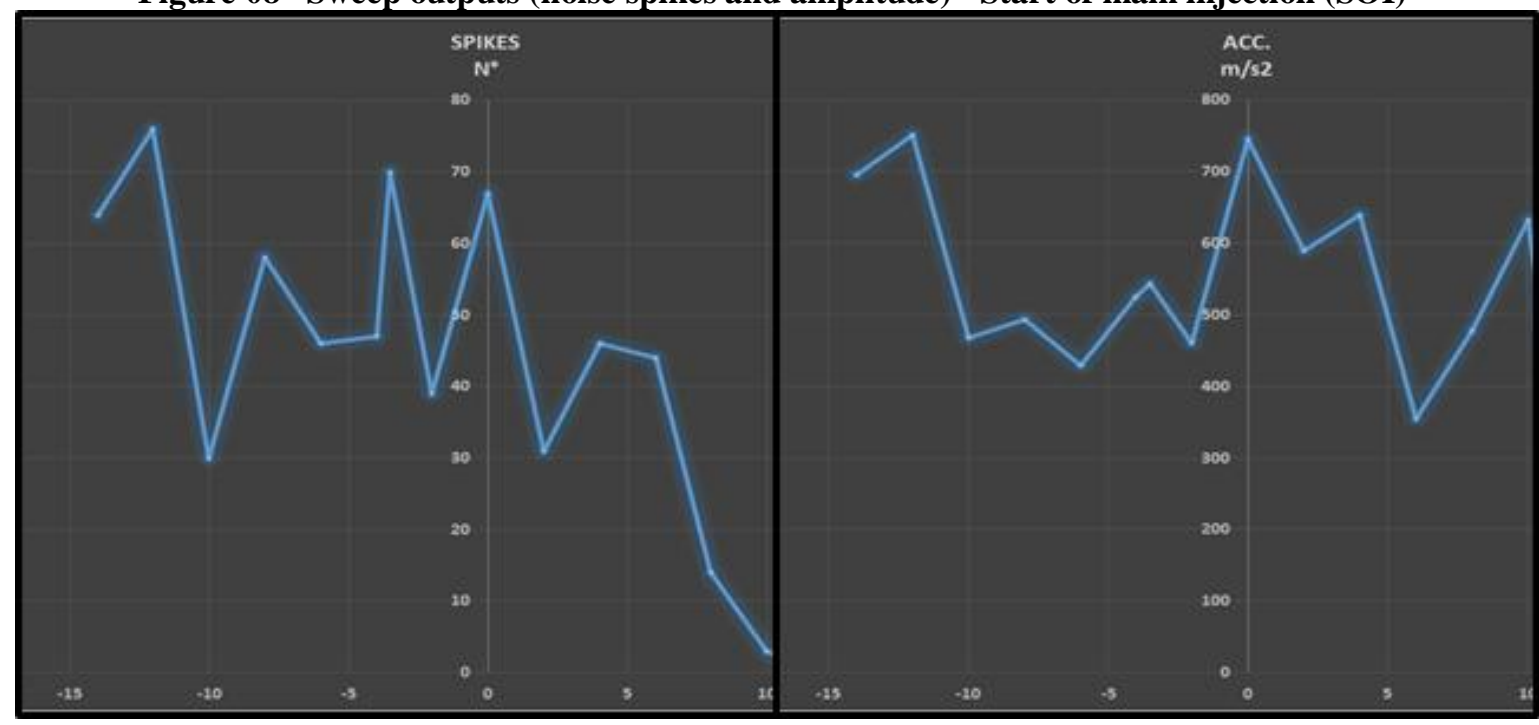

The outputs from the sweep revealed that start of main injection (SOI) and injection split are very relevant and should be factors better investigated. The methodology chosen for this investigation is the design of experiment (DoE).

\subsection{DoE methodology (Response Surface)}

The DoE method requires that a rigorous procedure be followed. Compared to traditional methods, DoE emphasizes careful thought and planning (brainstorming), instead of repeated trial-and-error [9]. 
From the sweeps, it was defined that injections would be split from current 2 injections (1 pre +1 main) to a total of 4 ( 2 pre +2 main) and so the DoE must evaluate the combinations for those injections in terms of quantity and timing.

Figure 09 and 10 below explains the splitting from current 2 to 4 injections. The figures also show combustion pressure over the time, where it is possible to notice a smoothing effect in the combustion pressure curve when injection is split in 4. As described in the introduction this smoothing effect in the pressure over the crank angle is beneficial for noise reduction.

Figure 09-Combustion pressure and injector current vs crank angle (baseline, 2 injections)

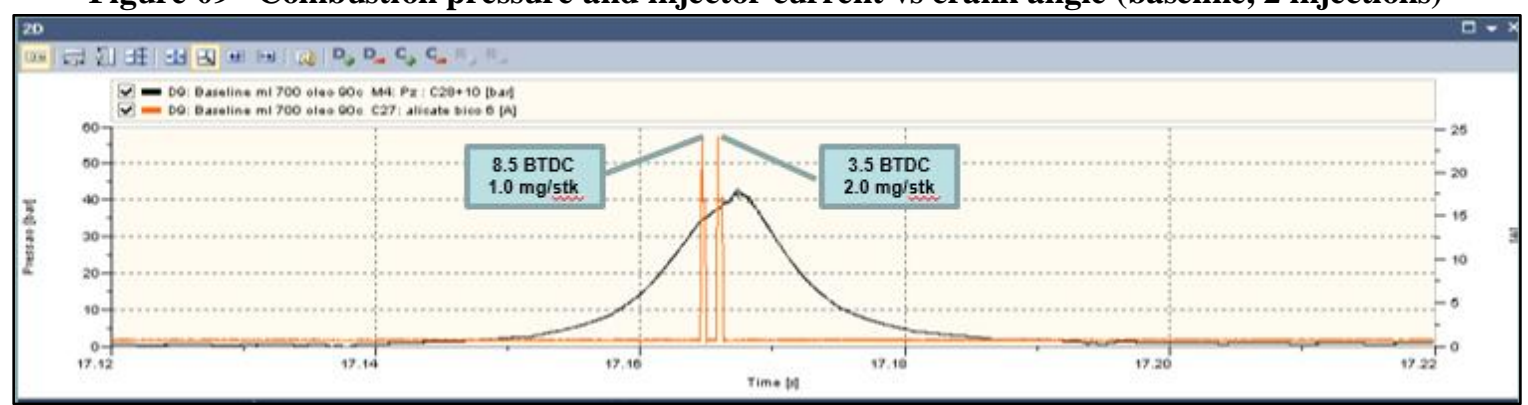

The black line represents combustion pressure over the time and red curve represents the injector current and so determines when it is opened and fueling.

Figure 10 -Combustion pressure and injector current vs crank angle (example for 4 injections)

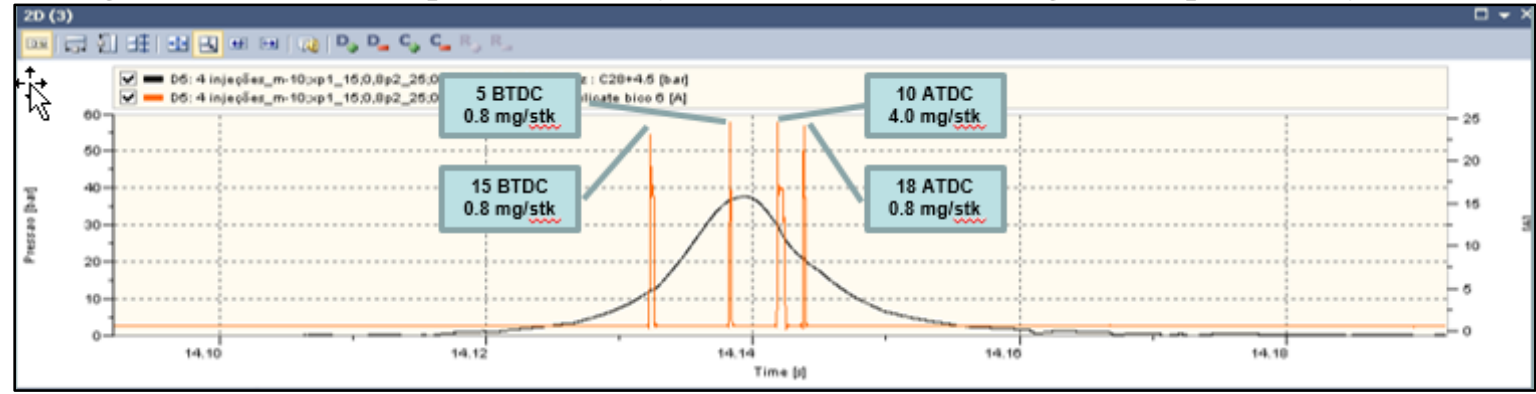

A big challenge of splitting from 2 to 4 injections is that the region where the noise is noticed is at low engine speeds and loads and so in a low fuel delivery area, especially at idle (700rpm). The fuel delivery at idle will vary depending on engine and accessories friction and will also depend on the combustion efficiency but just for a reference it is around 3.5 to $6.5 \mathrm{mg} / \mathrm{stroke}$ for a warmed-up engine. Lower engine temperatures result in a bit higher fuel delivery and the opposite will be noticed for higher engine temperatures. This low fuel delivery has then to be shared in 4 injections and to assure a reliable and consistent injection each injection should be higher than $0,8 \mathrm{mg} /$ stroke as per supplier documentation.

In terms of timing it shall be considered the minimal distance between each injection otherwise a collision can happen and the electronic control unit software would automatically cancel one of them.

Besides proven to be effective in reducing the noise a too late main injection results in a very high hydrocarbon (HC) formation and so in white smoke emission. It will be more sensitive in conditions where the exhaust gas is not hot enough to activate the HC 
conversion on the catalyst. Calibration strategy allows the late injection to be corrected based on coolant temperature but not based on exhaust gas temperature. To avoid white smoke formation this late injection shall be carefully defined.

Those fuel delivery, timing and late injection constraints are very important to define the levels to be applied for DoE combinations. So, a careful definition for the DoE parameters shall be done to assure a successful experiment.

After defining the input parameters and getting the baseline data a Response Surface Methodology (RSM) was planned.

The RSM explores the relationships between several explanatory variables and one or more response variables. In this study, a full factorial experiment was chosen, whose design consists of two or more factors, each one with discrete possible values (levels) and whose experimental units take on all possible combinations of these levels across all such factors.

Such an experiment allows the investigator to study the effect of each factor on the response variable, as well as the effects of interactions between factors on the response variable. For the vast majority of factorial experiments, each factor has only two levels. For example, with two factors each taking two levels, a factorial experiment would have four treatment combinations in total, and is usually called a $2 \times 2$ factorial design [10].

A total of 3 levels were considered (minimum, central and maximum values). Minimum and maximum levels were defined based on the sweeps and on the constraints regarding fuel delivery quantity and injection timing to avoid high level of $\mathrm{HC}$ formation, as previously explained in this chapter.

Table 3 shows each of the factors that will be evaluated and the levels that will be considered on this DoE study.

Table 3 - Factors and values considered for DoE experiment

\begin{tabular}{|l|c|c|c|}
\hline \multicolumn{1}{|c|}{ FACTORS } & MIN & MAX & STEP \\
\hline FUEL MASS (MAIN_2) & 0,8 & 1,8 & 0,5 \\
\hline FUEL MASS (PILOT 1) & 0,8 & 1,2 & 0,2 \\
\hline SOI (MAIN_1) & 0 & $12^{\circ}$ ATDC & 6 \\
\hline SOI DIF (MAIN_1_2) & 2 & $10^{\circ}$ & 4 \\
\hline SOI DIF (PILOT_1_MAIN_1) & 2,5 & 7,5 & 2,5 \\
\hline SOI DIF (PILOT_1_2) & 2,5 & 7,5 & 2,5 \\
\hline
\end{tabular}

The factors from this table had to be fine-tuned for each engine speed to avoid collision between injections and to assure minimal fuel delivery requirement for each injection.

Considering the ECU software strategy, the quantity of main injection 1 is not fixed, it will vary depending on test condition and will be a consequence from the other parameters. It will be the compensation value necessary to keep the engine running on the requested speed. 
The timing defined for pilot_2 (first injection) is related to the pilot_1 (second injection) which is based on the difference to main_1 (third injection). Main_2 timing (fourth injection) is related to main_1.

Table 4 shows the boundaries applied for this experiment where rail pressure was decided to be fixed in 300bar (best compromise from sweeps) and fuel delivery for pilot 2 was fixed in $0,8 \mathrm{mg} / \mathrm{stk}$. If this parameter is not fixed a much higher number of trials would be necessary.

Table 4 - Boundary conditions for DoE execution

\begin{tabular}{|l|c|}
\hline \multicolumn{2}{|c|}{ BOUNDARY CONDITIONS } \\
\hline Oil Temperature & 90 \\
\hline Clutch & YES \\
\hline Frame & YES \\
\hline Engine Speed (rpm) & $700 / 800 /$ \\
\hline Rail Pressure (bar) & $1000 / 1200$ \\
\hline Fuel mass PILOT_2 (mg/stk) & 0.8 \\
\hline
\end{tabular}

A total of 90 runs with combinations for all parameters was defined and executed on the dynamometer for 4 distinct engine speeds (700, 800, 1000 and 1200rpm).

One of the engine speeds will be showed in this work to exemplify the methodology and analysis conducted.

Table 5 shows the example of 90 runs defined for 800 rpm engine speed.

Table 5 - DoE partial experiment for 700rpm

\begin{tabular}{|c|c|c|c|c|c|c|}
\hline ORDEM & $\begin{array}{c}\text { SOI } \\
\text { MAIN_1 } \\
\text { ('CRK) }\end{array}$ & $\begin{array}{c}\text { SOI DIF } \\
\text { PILOT_1_MAIN_1 } \\
\text { ('CRK) }\end{array}$ & $\begin{array}{l}\text { SOI DIF } \\
\text { PILOT_1_2 } \\
\text { ('CRK) }\end{array}$ & $\begin{array}{l}\text { SOI DIF } \\
\text { MAIN_1_2 } \\
\text { ('CRK) }\end{array}$ & $\begin{array}{c}\text { FUEL MASS } \\
\text { PILOT_1 } \\
\text { (mg/stk) }\end{array}$ & $\begin{array}{c}\text { FUEL MASS } \\
\text { MAIN_2 } \\
\text { (mg/stk) }\end{array}$ \\
\hline 1 & 6,0 & 5,0 & 2,5 & 6,0 & 1,0 & 1,3 \\
\hline 2 & 6,0 & 5,0 & 5,0 & 6,0 & 1,0 & 1,3 \\
\hline 3 & 0,0 & 5,0 & 5,0 & 6,0 & 1,0 & 1,3 \\
\hline 4 & 6,0 & 5,0 & 5,0 & 6,0 & 1,0 & 1,8 \\
\hline 5 & 6,0 & 5,0 & 5,0 & 6,0 & 1,2 & 1,3 \\
\hline 6 & 6,0 & 5,0 & 5,0 & 2,0 & 1,0 & 1,3 \\
\hline 7 & 6,0 & 5,0 & 5,0 & 6,0 & 1,0 & 1,3 \\
\hline 8 & 6,0 & 5,0 & 5,0 & 6,0 & 1,0 & 1,3 \\
\hline 9 & 6,0 & 5,0 & 5,0 & 6,0 & 1,0 & 1,3 \\
\hline 10 & 6,0 & 5,0 & 5,0 & 6,0 & 1,0 & 0,8 \\
\hline • & - & • & • & $\cdot$ & . & - \\
\hline - & - & • & $\cdot$ & . & - & - \\
\hline - & - & - & - & - & - & - \\
\hline 80 & 12,0 & 7,5 & 7,5 & 10,0 & 0,8 & 0,8 \\
\hline 81 & 12,0 & 7,5 & 7,5 & 2,0 & 0,8 & 0,8 \\
\hline 82 & 12,0 & 2,5 & 2,5 & 2,0 & 1,2 & 1,8 \\
\hline 83 & 12,0 & 7,5 & 7,5 & 2,0 & 0,8 & 1,8 \\
\hline 84 & 12,0 & 2,5 & 2,5 & 10,0 & 0,8 & 0,8 \\
\hline 85 & 12,0 & 7,5 & 2,5 & 2,0 & 0,8 & 1,8 \\
\hline 86 & 6,0 & 5,0 & 5,0 & 6,0 & 1,0 & 1,3 \\
\hline 87 & 0,0 & 2,5 & 2,5 & 2,0 & 1,2 & 0,8 \\
\hline 88 & 0,0 & 7,5 & 7,5 & 2,0 & 1,2 & 0,8 \\
\hline 89 & 12,0 & 2,5 & 7,5 & 2,0 & 0,8 & 1,8 \\
\hline 90 & 0,0 & 7,5 & 2,5 & 2,0 & 0,8 & 0,8 \\
\hline
\end{tabular}


After running each selected mode, the data have been processed using MINITAB 17 tool. It is a statistics package developed at the Pennsylvania State University used at MWM for several studies and in this case to optimize combustion parameters on dynamometer using statistical methods.

The outputs considered for modelling the noise were number of spikes and amplitude $\left(\mathrm{m} / \mathrm{s}^{\wedge} 2\right)$.

The main effects behavior for each factor can be noticed in the graph 1.

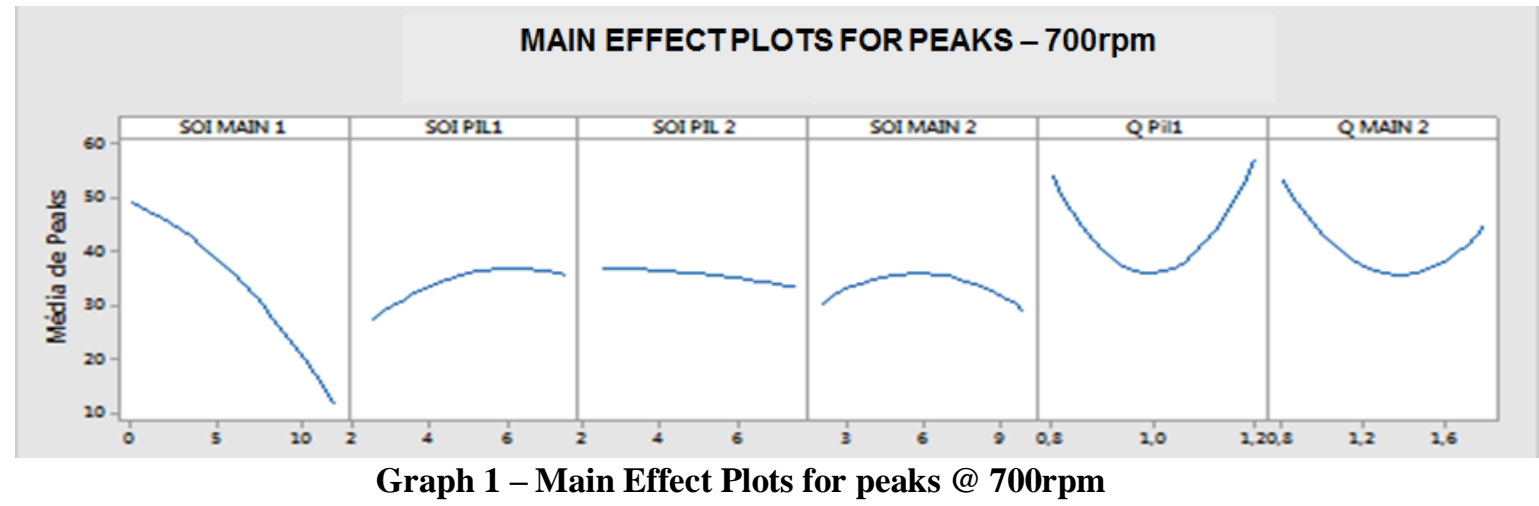

The result from main effects plots shows that the timing for main injection 1 is the most important variable to reduce noise occurrence, followed by pilot 1 and main 2 quantities.

Minitab is also able to predict the best optimization values to achieve a target on the response, in this case close to zero of noise occurrence. Graph 2 shows the optimization proposed by Minitab for each of the factors for 700rpm engine speed.

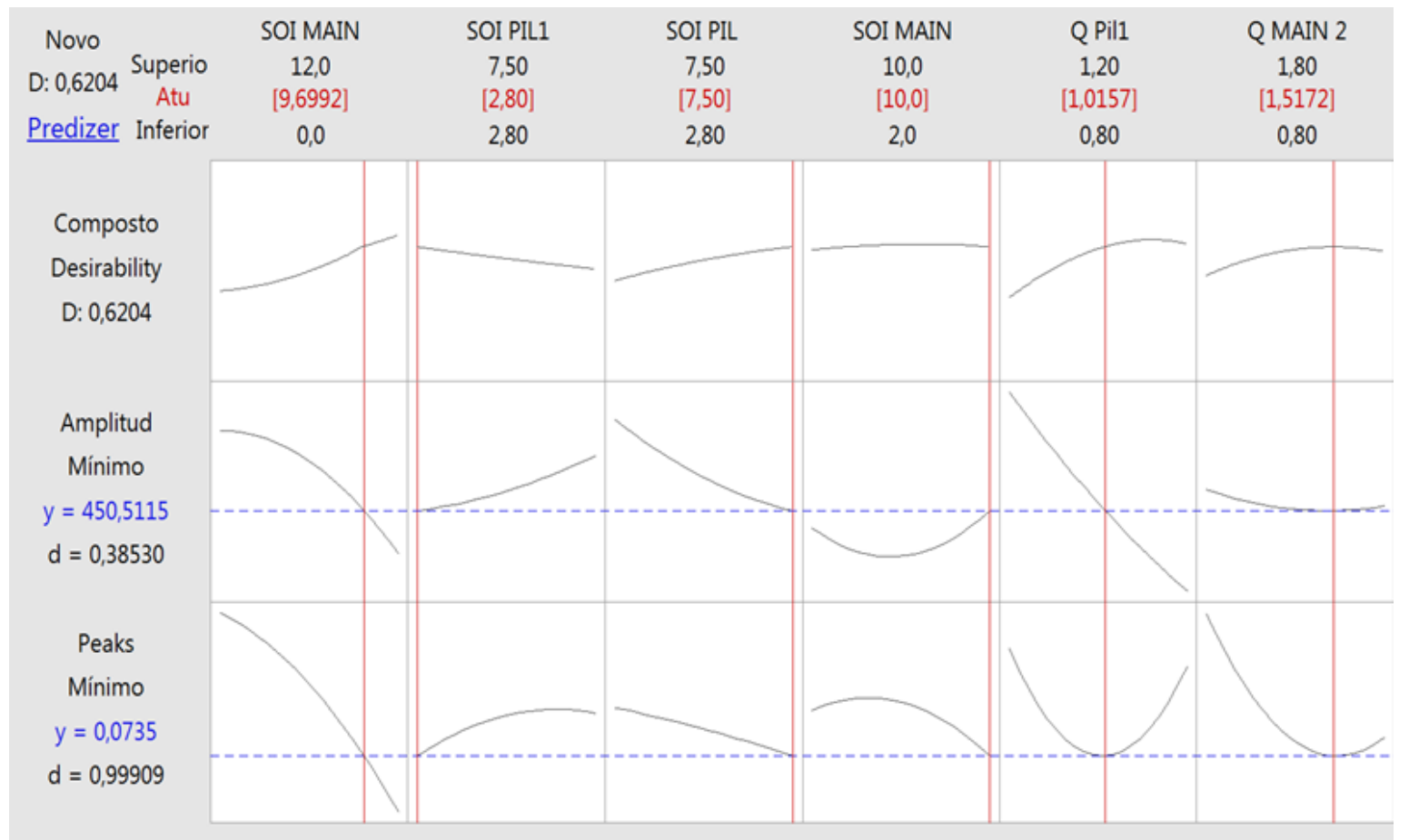

Graph 2 - Minitab optimization for peaks and amplitude @ 700rpm 
Unfortunately, the test bench used to run the DoE is not equipped with an emissions measurement device. In such case hydrocarbons, could also be measured and the optimization would be done also considering this output. For that reason and considering that there is a high risk of $\mathrm{HC}$ formation, the optimization points shall be interpreted by an engineer experienced with emissions or tested in an emissions dynamometer to measure $\mathrm{HC}$.

The risk is because the model recommends a very late main_1 injection timing, which results in a later main_2 and also impact on pilot injection timing (once all injections are based on the main_1 timing). Late injections results in an inefficient combustion where the fuel is not properly burnt leading to potential engine misfiring or high hydrocarbons formation.

Same kind of analysis were performed for the remaining engine speeds (800, 1000 and 1200rpm) and the optimized points were determined as well.

\subsection{Model Validation}

Aiming to validate the results from DoE, some of the modelled combustion values (from high peaks to low peaks) were listed and then tested on the test bench. The table 6 summarizes the expected results from the models versus the real ones.

Table 6 - Model validation

\begin{tabular}{|c|c|c|c|c|c|c|c|c|c|c|}
\hline \multirow{2}{*}{$\begin{array}{c}700 \mathrm{rpm} \\
\text { Test number }\end{array}$} & \multicolumn{6}{|c|}{ Inputs } & \multicolumn{4}{|c|}{ Outputs } \\
\hline & $\begin{array}{c}\text { SOI } \\
\text { MAIN_1 } \\
\left({ }^{\circ} \mathrm{CRK}\right)\end{array}$ & $\left|\begin{array}{c}\text { SOI DIF } \\
\text { PIL1_MAIN } \\
{ }_{-}^{1}\left({ }^{\circ} \mathrm{C} \text { CRK }\right)\end{array}\right|$ & $\begin{array}{c}\text { SOI DIF } \\
\text { PIL1_PIL_2 } \\
\text { ("CRK) }\end{array}$ & $\begin{array}{l}\text { SOI DIF } \\
\text { MAIN 1_2 } \\
\left.\text { ( }{ }^{\circ} \mathrm{CRK}\right)\end{array}$ & $\begin{array}{l}\text { FUEL MASS } \\
\text { PILOT_1 } \\
\text { (mg/stk) }\end{array}$ & $\begin{array}{c}\text { FUEL MASS } \\
\text { MAIN_2 } \\
\text { (mg/stk) }\end{array}$ & $\begin{array}{l}\text { Real } \\
\text { Peaks } \\
-15 s\end{array}$ & $\begin{array}{l}\text { Model } \\
\text { Peaks } \\
-15 \mathrm{~s}\end{array}$ & $\begin{array}{l}\text { Real avg. } \\
\text { amplitude- } \\
15 \mathrm{~s}^{2}\left(\mathrm{~m} / \mathrm{s}^{\wedge} 2\right)\end{array}$ & $\begin{array}{l}\text { Model avg. } \\
\text { amplitude- } \\
15 \mathrm{~s}\left(\mathrm{~m} / \mathrm{s}^{\wedge} 2\right.\end{array}$ \\
\hline 1 & -12 & 2,8 & 7,5 & -10 & 1,13 & 1,77 & 2 & 0 & 513 & 0 \\
\hline 2 & -10 & 4 & 3,3 & -2 & 0,80 & 1,50 & 0 & 34 & 0 & 547 \\
\hline 3 & -6 & 3 & 3 & -2 & 0,80 & 1,32 & 8 & 43 & 406 & 559 \\
\hline 6 & -6 & 7,5 & 2,8 & -5 & 0,80 & 0,80 & 7 & 61 & 577 & 500 \\
\hline 7 & -7 & 2,8 & 2,8 & -5 & 1,00 & 1,30 & 3 & 26 & 625 & 548 \\
\hline
\end{tabular}

From the table, it is possible to notice that model does not fit well for all evaluated engine speeds. However, DoE was very useful for showing the trend/main effects of each parameter and so defining the values to be brought for each dataset configuration. The main reason for the model bad accuracy is that the noise occurrence is random and shows different behavior even for the same test condition (not repeatable). Along the DoE study it was also noticed that the engine got worse in terms of noise and that could have compromised the results.

\subsection{Dataset Proposals}

Considering the outputs from the DoE's, the feeling developed along the tests, the influence on $\mathrm{HC}$ and fuel consumption and customer requirements, 5 dataset proposals have been prepared. Proposal 1 and 2 has same combustion calibration but one with idle at 800rpm and the other keeping the current 700rpm for idle. Proposal 3 represents a combustion that would not be fully effective in noise occurrence but will reduce $\mathrm{HC}$ formation. Proposal 4 represents also a not fully effective solution for noise but would be the one with less penalty on fuel consumption. Proposal 5 is a customer requirement where the dataset is like proposal 2 but with the changes only applied from 700 to 750rpm. Table 7 below shows the details 
for proposals 1,2 and 5. Main idea is to take those proposals and evaluate it in terms of emissions and noise solving effectiveness.

Table 7 - Datasets proposal 1 and 2

\begin{tabular}{|c|c|c|c|c|c|c|c|c|c|c|c|c|c|}
\hline \multirow[b]{2}{*}{$\begin{array}{c}\text { Engine } \\
\text { Speed (rpm) }\end{array}$} & \multicolumn{6}{|c|}{ Inputs } & \multicolumn{7}{|c|}{ Outputs } \\
\hline & $\begin{array}{c}\text { SOI } \\
\text { MaIN_1 } \\
\text { ("CRK) }\end{array}$ & $\begin{array}{c}\text { SOI DIF } \\
\text { PuL_.MAIN } \\
1 \text { ["CRK) }^{\circ}\end{array}$ & $\begin{array}{c}\text { Sol DIF } \\
\text { PIU__PIL_2 } \\
\text { ["CRK) }\end{array}$ & $\begin{array}{c}\text { SOI DIF } \\
\text { MAIN } 1.2 \\
\text { ("Cs:) }\end{array}$ & $\begin{array}{c}\text { FUEL MASS } \\
\text { PILOT_1 } \\
(\mathrm{mg} / \mathrm{stk})\end{array}$ & \begin{tabular}{|c|} 
FUEL MASS \\
Main_2 \\
(mg/stk)
\end{tabular} & Picos-15s & $\begin{array}{c}\text { Amplitude } \\
\text { média } \\
(\mathrm{m} / \mathrm{s} \times 2)\end{array}$ & $\begin{array}{l}\text { HC EO } \\
\text { (ppm) }\end{array}$ & $\begin{array}{l}\text { HC TP } \\
\text { (ppm) }\end{array}$ & $\begin{array}{l}\text { COEO } \\
\text { (gpen) }\end{array}$ & $\begin{array}{l}\text { COTP } \\
\text { (ppm) }\end{array}$ & \begin{tabular}{|c|} 
Fuel \\
Consumption \\
$(\mathrm{kg} / \mathrm{h})$ \\
\end{tabular} \\
\hline 700 & -10 & 4 & 3,3 & -2 & 0,80 & 1,50 & 0 & 0 & 169 & 26 & $m$ & 36 & 1,52 \\
\hline BL -700 & 3,5 & 5 & - & - & 1,00 & - & 54 & 694 & 76 & 13 & 84 & 13 & 1,45 \\
\hline 800 & -10 & 4 & 3,3 & -2 & 0,80 & 1,50 & 4 & 364 & 181 & 25 & 198 & 31 & 1,79 \\
\hline $8 t-800$ & 3 & 5 & - & - & 1,00 & - & 57 & $6 \pi$ & 68 & 11 & 94 & 15 & 1,68 \\
\hline 1080 & -10 & 5 & 4 & -2 & 0,80 & 1,40 & 0 & 0 & $m 2$ & 32 & 265 & 35 & 2,38 \\
\hline BL -1000 & 3 & 5 & - & - & 1,00 & - & 76 & 680 & $\pi$ & 11 & 101 & 14 & 2,09 \\
\hline
\end{tabular}

Graph 3 shows a comparison between current dataset and proposal 1 and 2 in terms of HC formation in engine out (HC EO) and system out (HC SO - aftertreatment) and also the fuel consumption. Noise is significantly reduced on these proposals but at a cost of an increment on $\mathrm{HC}$ formation and fuel consumption.

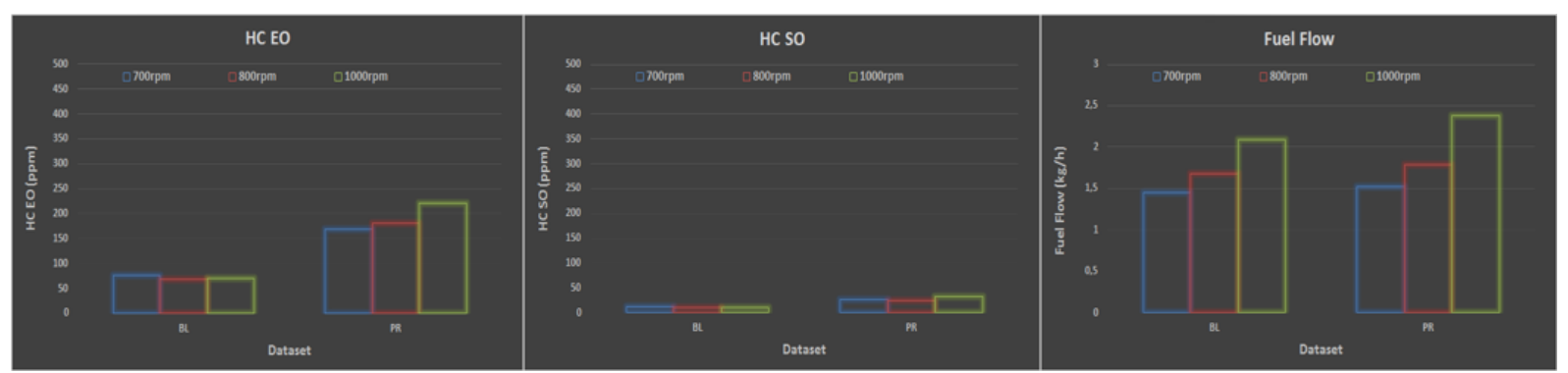

Graph 3 - HC and fuel flow results for dataset proposals 1 and 2

Every dataset proposals have been evaluated in terms of emissions legislation (ESC and ETC) and even the more aggressive calibrations to solve the noise issue (proposal 1 and 2) had been approved. Graph 4 shows a zoom in the ESC cycle just in idle speed measurement (this is the only one affected from the 13 points). It is possible to realize that proposals $1 \mathrm{ad}$ 2 has higher engine out $\mathrm{HC}$ levels but almost same result when evaluating HC formation on the system out (aftertreatment influence on converting HC).

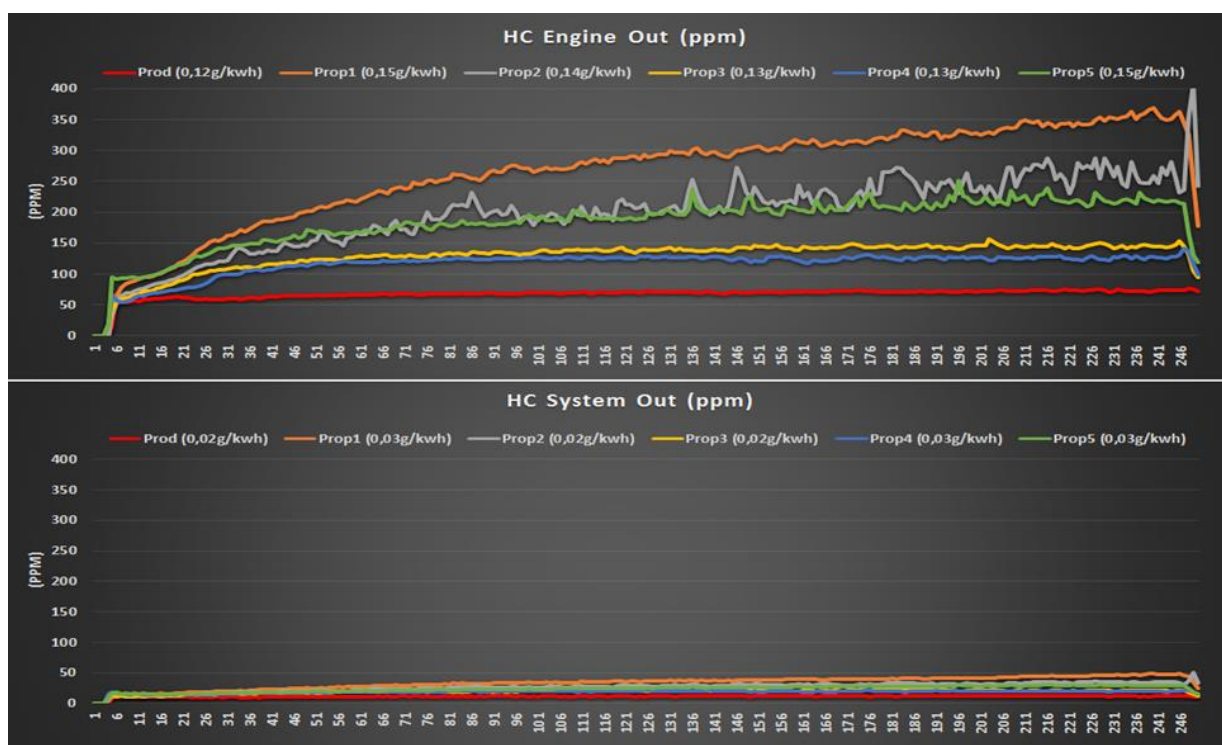

Graph 4 - HC formation in idle point of ESC cycle 
From the table 7 and graphs 3 and 4 it is possible to realize that aftertreatment system is very helpful in converting the HC. This happens mainly when the catalyst is heated-up, which is the case in ESC and ETC tests. In case the exhaust gas temperature is not warm enough, HC conversion will be much lower and so white smoke formation could be an issue.

Datasets proposals 3 and 4 were not considered for tests in the field once they still present noise occurrences. Dataset proposal 1 was also disregarded as customer did not desire to change the engine idle speed which could lead to customer complaint. Proposal 5 was also not effective to cover the noise in the fully range and so was also disregarded. Dataset proposal 2 was the one chosen to be tested on the vehicles in the field that were presenting noise complaints. The results are shown in next chapter.

\section{RESULTS}

A dataset update plan was arranged by the customer and dealers for several vehicles in the field which were presenting noise complaint.

The plan was first to confirm that the noise was related to bearing knock by using exactly same method from dyno and then to update the electronic control unit dataset. This updating work started in May 2016 and was performed in several cities around the country.

After the dataset update the engine noise should be subjective evaluated by the engineers and mechanics and then recorded for objective analysis. Apart of the noise effectiveness the updated vehicle should be evaluated in terms of performance, $\mathrm{HC}$ smell and white smoke formation. As previously mentioned a dataset with $6^{\text {th }}$ cylinder injector shut-off was also prepared in parallel to this combustion research. So, most of the vehicles that were updated with the new proposed combustion was also evaluated with this injector shut off option. Idea was to have a back plan in case combustion solution did not fix the noise issue. Based on field results it should be decided which option will be applied for massive production.

The result in terms of noise obtained in one of the vehicles can be observed in the graph 5 for the dataset proposal 2.

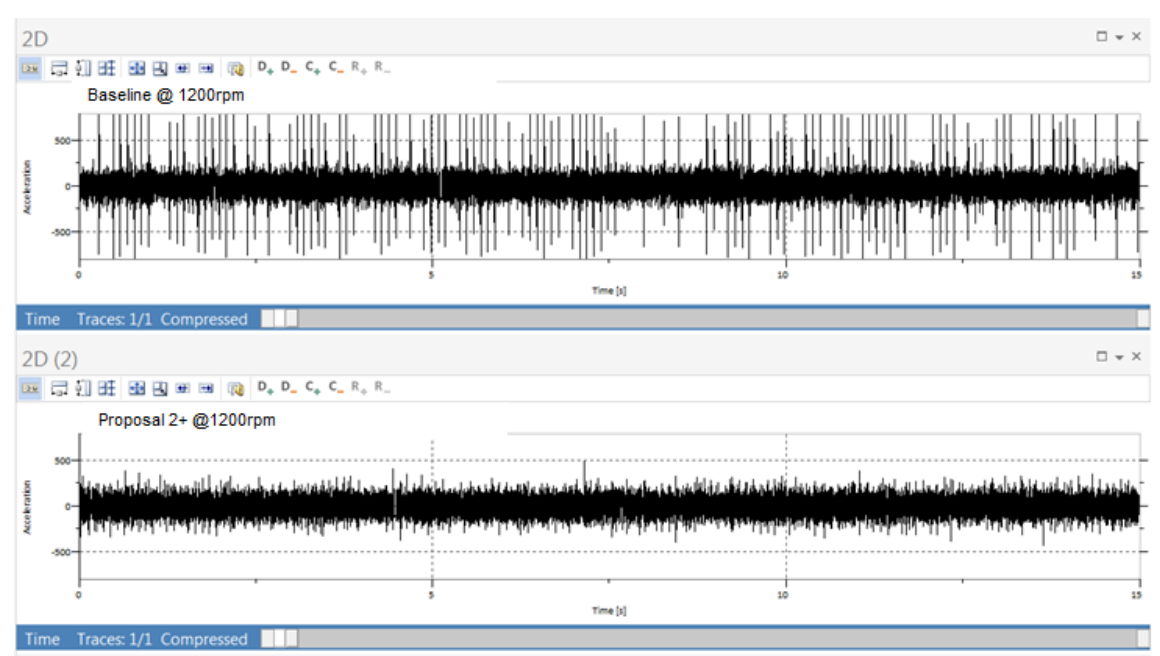

Graph 5 - Baseline vs dataset proposal 2 comparison in terms of vibration 
As expected based on dynamometer research, the noise was eliminated after applying the new combustion parameters dataset.

The result obtained for injector shut-off proposal was also successful in eliminating the noise as shown in graph 6.

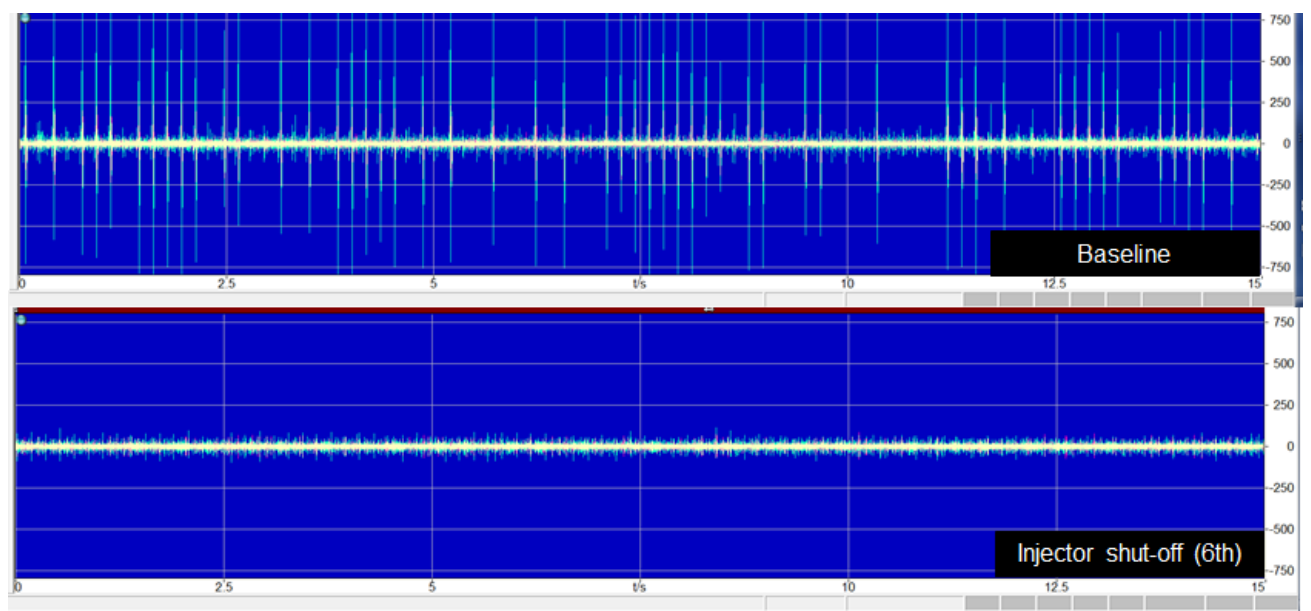

Graph 6 - Baseline vs injector shut off strategy comparison in terms of vibration

Considering only the noise issue, both options have shown successful results. The decision on which dataset should be implemented as final solution shall also take in consideration performance and drivability aspects, $\mathrm{HC}$ smell and white smoke formation.

In one of the vehicle update trip, a very specific situation was found regarding the way how the vehicle was used and was determinant for defining which option would be applied in the field as the effective solution. It was related to a fleet that transports goods from one side of the road to the Rio Grande Dockyard located just in the other side of the road. The duty cycle of the vehicle was no more than $10 \mathrm{~km}$ with very long periods of idling while loading and unloading the vehicle. That kind of operation leads to low exhaust temperatures. Rio Grande is a sea city located in the south of Brazil and weather tends to be cold specially in the period were the dataset was updated. That combination of cold weather, high humidity, long idling and low exhaust temperature profile resulted in a bad HC conversion from the catalyst and so in white smoke formation for the dataset with the new proposed combustion.

\section{CONCLUSIONS}

After several tests in test bench and vehicles, splitting from 2 to 4 injections has proven to be effective for reducing bearing knock noise due to the smoothness of combustion pressure. The solution complies with emissions legislation and was accepted by the customer. The negative effect is that such proposal lead to higher hydrocarbons emissions and in one specific application resulted in white smoke formation, due to the combination of duty cycle, long idling, low exhaust temperatures, cold weather and high humidity.

Unfortunately, the electronic control software does not have any strategy that links combustion corrections with exhaust temperatures, in such case, combustion could be corrected just while the exhaust temperature was not high enough to convert the HC. However, such correction would result in bit higher noise occurrence but still better than the baseline. 
In parallel a dataset for shutting off the $6^{\text {th }}$ injector was also developed and tested together with proposed combustion dataset. In terms of noise solution, this strategy had similar results to the other proposal. No drawbacks were noticed from this strategy, which was also evaluated in terms of emissions and fuel consumption impact.

Considering the overall results from the $6^{\text {th }}$ cylinder injector shut off strategy it was decided to move forward with this option for massive production.

All vehicles with bearing knock noise complaint were updated in the field and solution were proven to be effective in solving the problem with any negative effect.

In future programs a better integration between the NVH and calibration team is recommended to assure the best trade-off between performance, emissions and acoustics.

\section{NEXT STEPS}

Develop a software strategy that allows combustion to be corrected also based in the exhaust temperature, in case such sensor is available.

Regarding noise research further experimental or computational analysis can be performed to better understand the natural and operational vibration modes of the rotational parts such as crankshaft, torsional vibration damper, flywheel and clutch.

For better evaluation and characterization of sound quality it is recommended to apply a psychoacoustics metric, like impulsiveness, and/or a jury test as well. 


\section{REFERENCES}

[1] FEV website - Impulsive noise on diesel engines

[2] S. G. Dogan - Loose part vibration in vehicle transmissions - Gear rattle, University of Stuttgart - Germany

[3] Ö. Kilicay - Predicting impact conditions due to Bearing clearances in linkage mechanisms - Doctor of Philosophy in the Faculty of Engineering of the University of London

[4] J. N. Chi - Non-Invasive Diagnostics of Excessive Bearing Clearance in Reciprocating Machinery - B.E.Sc., The University of Western Ontario, Canada (1993)

[5] Z. Stanik, J. Warczek, - Application of Vibration Signals in The Diagnosis of Combustion Engines - Exploitation Practices - Journal of KONES Powertrain and Transport, Vol. 18, No. 32011

[6] O. Sauvagea, A. Lauracb, M.-C. Bezata, V. Roussariea and P. Guillemainc - Diesel knock noise from combustion phenomenon to perceived signals - Proceedings of the Acoustics 2012 Nantes Conference

[7] J. Chen, R. Randall - Vibration Signal Processing of Piston Slap and Bearing Knock in IC Engines - School of Mechanical and Manufacturing Engineering, University of New South Wales, Sydney - Australia.

[8] J. Chen, R. Randall - Intelligent diagnosis of bearing knock faults in internal combustion engines using vibration simulation, Institute of Sound and Vibration Research, University of Southampton, Southampton, UK - School of Mechanical and Manufacturing Engineering, University of New South Wales, Sydney - Australia

[9] YAN, J., ROGALLA, R., \& KRAMER, T., "Diesel Combustion and Transient Emissions Optimization Using Taguchi Methods", SAE Technical Paper Series, 930600, 1993.

[10] LEAL, S., LUZ, F., \& CAPANA, G., "Fuel Consumption Optimization in a MD Diesel Engine Using Analytical Tools", SAE Technical Paper Series, 2015-36-0321.

\section{BIBLIOGRAPHY:}

[11] Valkonen, Antti - Oil Film Pressure in Hydrodynamic Journal Bearings, Helsinki University of Technology, Doctoral Tesis

[12] Salamone, Dana J. - Journal bearing design types and their applications to turbomachinery, Centritech Corporation, Houston Texas

[13] Internal combustion engine Handbook - Basics, components, systems and perspectiver - SAE International - Chapter 7.19-2002 edition.

[14] Georges, S. N. Y., Ruídos e vibrações veiculares - 2005 edition 